\title{
Research Advances in Photocatalysis of Inorganic Hollow Spheres
}

\author{
Ting Tian1, Jing Hu1,2*, Zuobing Xiao1,2 \\ ${ }^{1}$ School of Perfume and Aroma Technology, Shanghai Institute of Technology, Shanghai, China \\ ${ }^{2}$ Shanghai Research Institute of Fragrance \& Flavor Industry, Shanghai, China \\ Email: hujing@sit.edu.cn
}

Received 29 August 2014; revised 30 September 2014; accepted 30 October 2014

Academic Editor: Yarub Al-Douri, University Malaysia Perlis, Malaysia

Copyright (C) 2014 by authors and Scientific Research Publishing Inc.

This work is licensed under the Creative Commons Attribution International License (CC BY). http://creativecommons.org/licenses/by/4.0/

(c) (i) Open Access

\begin{abstract}
Inorganic hollow spheres have shown their superiority in photocatalytic area due to the large specific surface area, controllable structure and their own special optical, electrical, magnetic properties. According to the classification of inorganic hollow spheres as photocatalysts, recent research progress and application status have been summarized in this paper. At last, the future developments of inorganic hollow spheres in photocatalytic field have been discussed.
\end{abstract}

\section{Keywords}

\section{Inorganic Hollow Spheres, Photocatalysis, Application, Progress}

\section{Introduction}

Hollow spheres, also known as 0D nanomaterial, were spheroidal aggregates with hollow structure assembled by their 1D nanomaterial. Due to their characteristics of controlled morphology, uniform size, large specific surface area and low density, extensive attention has been paid so far in material area [1]-[5]. Particularly, inorganic hollow spheres with special optical, electrical, magnetic, mechanical and catalytic properties have been widely used in bio-pharmaceutical, catalyst, carrier, controlled release, photonic crystal, electrochemistry and environmental protection [6]-[11]. Under the urgent situation of environmental pollution, inorganic hollow spheres as photocatalyst turned into a way to solve environmental problems. Inorganic hollow spheres have peculiar hierarchical porous structure, which makes reactant molecules easily transfer to the active sites of porous wall to improve their photocatalytic efficiency. Moreover, the hollow structure allows multiple reflections of ul-

\footnotetext{
${ }^{*}$ Corresponding author.
} 
traviolet and visible light in inner hole to enhance utilization of light [12]. In this paper, according to the classification of photocatalytic inorganic hollow spheres, recent research progress has been introduced and application status has been concluded. The future developments of inorganic hollow spheres in photocatalytic field have been discussed.

\section{Metal Oxide Hollow Spheres}

\subsection{Titanium Dioxide $\left(\mathrm{TiO}_{2}\right)$}

The valence and conduction band of $\mathrm{TiO}_{2}$ is composed of the filled 2p orbitals of oxygen and 3d, $4 \mathrm{~s}$ and $4 \mathrm{p}$ orbitals of titanium, respectively. Its energy gap is about $3.2 \mathrm{eV}$, which makes $\mathrm{TiO}_{2}$ being the most promising photocatalyst. The specific band potential gives its strong oxidizing property, high chemical durability and photoelectric conversion efficiency, as well as price superiority. Furthermore, the large specific surface area and low density of hollow structure can effectively enhance photocatalytic activity of $\mathrm{TiO}_{2}$ [13]. The $\mathrm{TiO}_{2}$ hollow spheres obtained by $\mathrm{Li}$ and co-workers can completely remove azo-dye Rhodamine $\mathrm{B}$ (Rh B) under visible light irradiation in 240 min, which is only 50\% for DeGussa P25 under the same experimental conditions [14]. However, $\mathrm{TiO}_{2}$ can be excited only under ultraviolet light (less than $5 \%$ of the full solar spectrum). Besides, easily recombination of photogenerated electrons and holes and low interfacial charge transfer rate into $\mathrm{TiO}_{2}$ lead to reduction of photocatalytic efficiency. Therefore, three principal methods have been used to enhance photocatalytic activity of $\mathrm{TiO}_{2}$ : ameliorate crystal composition, enlarge specific surface area and modify surface of $\mathrm{TiO}_{2}$ hollow sphere. In the process of crystal growth, the more exposed of $\{001\}$ and $\{110\}$ facets which have high interface energy means higher photocatalytic activity [15]-[17]. Wang et al. [18] prepared $\mathrm{TiO}_{2}$ hollow sphere with sixty percent exposure of $\{001\}$ facets, which has higher photocatalytic activity than that of commercial photocatalyst P25. Figure 1 shows XRD pattern , SEM images and TEM images of anatase $\mathrm{TiO}_{2}$ hollow microspheres with exposed $\{001\}$ facets. Jiao et al. [19] discovered that the interface energy of $\{116\}$ facets was similar to that of $\{110\}$ facets through X-ray diffraction analysis. The photocatalytic property of $\mathrm{TiO}_{2}$ hollow sphere consisting of highly active $\{116\}$ plane-oriented crystallites exceed that of common $\mathrm{TiO}_{2}$ hollow sphere, because curved $\{116\}$ facets can multi-reflect incident light to enhance capture rate. $\mathrm{The}^{\mathrm{TiO}_{2}}$ hollow spheres with special morphology were obtained to add specific surface area thus improve photocatalytic performance such as multi-shell structure [20] [21]. Tao et al. [22] prepared flower-like $\mathrm{TiO}_{2}$ hollow spheres assembled by nanosheet, which has a higher surface area $\left(65 \mathrm{~m}^{2} / \mathrm{g}\right)$ than that value of commercial $\mathrm{TiO}_{2}\left(7 \mathrm{~m}^{2} / \mathrm{g}\right)$. Therefore, Degradation performance of methyl orange (MO) by the flower-like $\mathrm{TiO}_{2}$ hollow sphere is better than that of commercial $\mathrm{TiO}_{2}$.
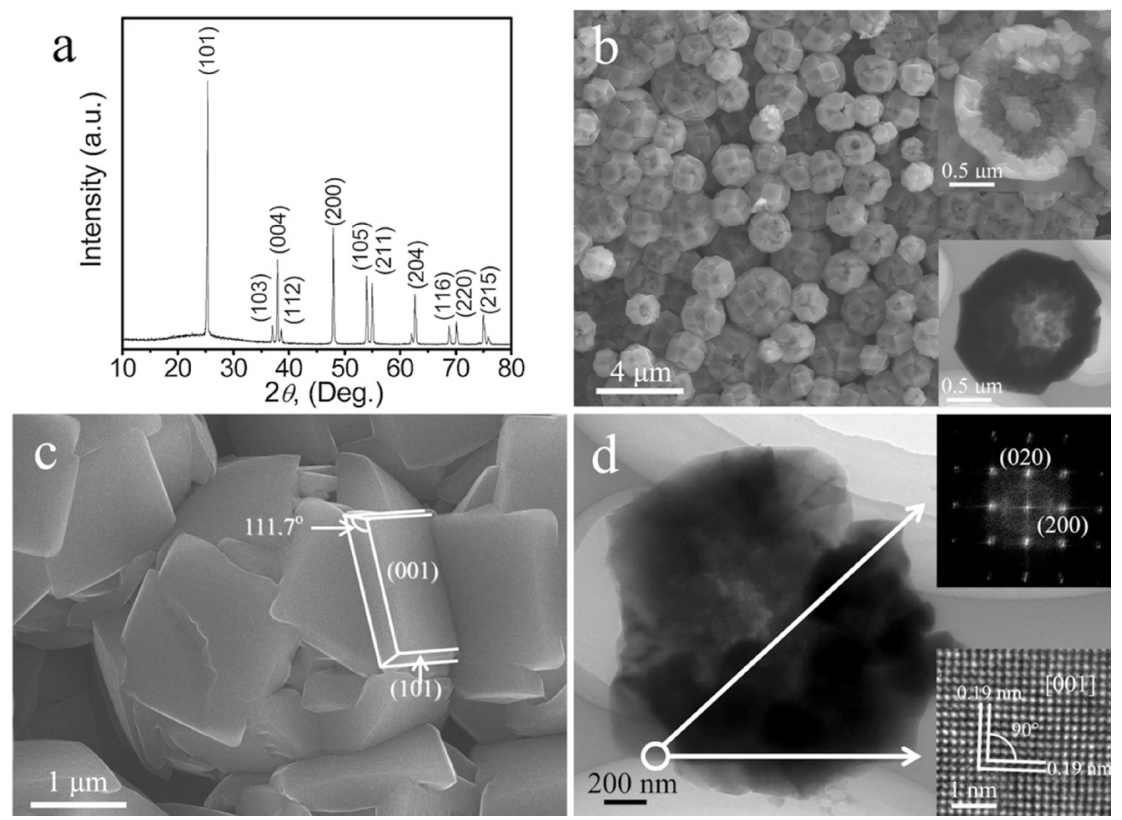

Figure 1. XRD pattern (a), SEM images (b) (c) and TEM images of anatase $\mathrm{TiO}_{2}$ hollow microspheres with exposed $\{001\}$ facets (d) [18]. 
In recent years, surface modification of $\mathrm{TiO}_{2}$ hollow spheres has been widely researched to improve their photocatalytic efficiency. 1) Doping metal ion into $\mathrm{TiO}_{2}$ lattice to create defect position can capture electron from conduction band, reduce recombination of photogenerated electrons and holes in photocatalytic process and accelerate interface charge-transfer to raise photocatalytic activity. Transition metal, noble metal and rareearth metal can be incorporate elements, such as vanadium, platinum, cerium, neodymium, etc. Vanadiumdoped $\mathrm{TiO}_{2}$ hollow spheres prepared by Liu et al. [23] can quickly degrade methylene blue under visible-light irradiation to show their excellent photocatalytic activity and renewability. Feng and coworkers [24] prepared platinum doped $\mathrm{TiO}_{2}$ hollow spheres using carbon spheres as templates through hydrothermal precipitation method and adding hydrazine hydrate to reduce chlomplatinie acid. When platinum-doped content is $2.0 \%$, the decolorization rate of obtained $\mathrm{TiO}_{2}$ hollow spheres can achieve $100 \%$ under 2 hour ultraviolet light irradiation. Wang and coworkers [25] [26] use carbon spheres to prepare cerium and neodymium doped $\mathrm{TiO}_{2}$ hollow spheres with dope concentration of $4 \%$ and $3.9 \%$ and apply them to dye decomposition. Results show that the apparent rate constant of doped $\mathrm{TiO}_{2}$ hollow spheres in degrading dye is 31 and 9 times as that of P25. 2) Non-metal elements also can be doped, such as boron [27], nitrogen [28] [29], carbon [30] [31], fluorine [32], etc. Non-metal ion possess relatively high energy orbit. Once doped it can replace some part of oxygen in the $\mathrm{TiO}_{2}$ lattice, thus bring in new level to lower energy gap and extend absorption wavelength. Yu et al. [33] prepared trifluoroacetic acid modified $\mathrm{TiO}_{2}$ hollow spheres by one-pot hydrothermal treatment using titanium sulfate as titanium source, the photocatalytic activity of which manifested 2 times higher than that of P25. In order to further improve photocatalytic activity of $\mathrm{TiO}_{2}$ hollow spheres, two or more kinds of ion can be doped to simultaneously provide electrons and holes trap to effectively suppress the recombination. Wang et al. [34] prepared cerium and nitrogen co-doped $\mathrm{TiO}_{2}$ hollow spheres owning enhanced visible light photocatalytic performance in dye X-3B decolorization because nitrogen decreased the energy gap and photogenerated electron of $\mathrm{TiO}_{2}$ valence band can transfer to the $4 \mathrm{f}$ orbit of cerium to inhibiting recombination. 3) Noble metal particles deposited onto the surface of $\mathrm{TiO}_{2}$ hollow spheres can take advantage of their surface plasmon resonance to extend absorption wavelength to visible light region, therefore enhance photocatalytic performance [35] [36]. Xiang et al. [37] combine microwave and hydrothermal treatment to prepare $\mathrm{TiO}_{2}$ hollow spheres with silver (Ag) nanoparticles deposited onto the surface, which have obvious absorption in the wavelength region from 400 to $600 \mathrm{~nm}$ and show better photocatalytic activity than pure $\mathrm{TiO}_{2}$ and commercial Degussa P25 powders. The single-crystalline anatase $\mathrm{TiO}_{2}$ hollow nano-hemispheres with bimetallic Ag/Pt nanoparticles uniformly loaded on both interior and exterior of the nano-hemispheres prepared by Jiang and co-workers exhibited excellent photocatalytic ability in the degradation of $\mathrm{Rh} \mathrm{B} /$ ciprofloxacin (RhB/CIP) and hydrogen generation [38]. Figure 2 shows $\mathrm{H}_{2}$ production rates of $\mathrm{TiO}_{2}, \mathrm{Ag} @ \mathrm{TiO}_{2}, \mathrm{Pt} @ \mathrm{TiO}_{2}$ and $\mathrm{Ag} / \mathrm{Pt} @ \mathrm{TiO}_{2}$ photocatalysts with $\mathrm{CH}_{3} \mathrm{OH}$ as the sacrificial reagent.

\subsection{Other Metal Oxide}

Oxide of d region elements also own good photocatalytic activity, such as vanadium pentoxide [39], manganese dioxide [40], nickel oxide [41], tantalum oxide [42], ferric oxide $\left(\mathrm{Fe}_{2} \mathrm{O}_{3}\right)$ [43], copper (I) oxide $\left(\mathrm{Cu}_{2} \mathrm{O}\right)$ [44], tungsten oxide $\left(\mathrm{WO}_{3}\right)$ [45] [46], zinc oxide (ZnO) [47] [48], etc. Patrinoiu et al. [49] impregnated carbonaceous

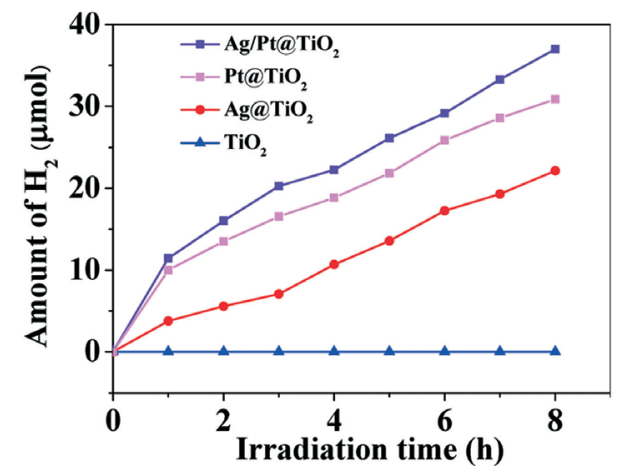

Figure 2. $\mathrm{H}_{2}$ production rates of $\mathrm{TiO}_{2}, \mathrm{Ag} @ \mathrm{TiO}_{2}$, of and $\mathrm{Ag} / \mathrm{Pt} @ \mathrm{TiO}_{2}$ photocatalysts with $\mathrm{CH}_{3} \mathrm{OH}$ as sacrificial reagent [38]. 
spheres templates with hydrated zinc acetate and then removed templates by thermal treatment to obtain zinc oxide hollow spheres. Under ultraviolet light irradiation, the phenol mineralization rate by zinc oxide hollow spheres can exceed 80\%, which notably superior to commercial zinc oxide (Merck). Figure 3 shows effects of $\mathrm{ZnO}$ hollow sphere (HS) and commercial product (Merck) nature on degradation of phenol under same irradiation conditions. Cao and co-workers [50] prepared hexagonal $\alpha-\mathrm{Fe}_{2} \mathrm{O}_{3}$ hollow spheres assembled by nanosheets through a microwave-assisted solvothermal route using ferric trichloride hexahydrate, sodium hydroxide and sodium dodecyl benzene sulfonate as raw materials and ethylene glycol as solvent. Degradation percentage of salicylic acid by the obtained hollow spheres under ultraviolet light in one hour can reach $60 \%$ and overtop $40 \%$ after using 2 times. Li et al. [51] prepared $\mathrm{Nb}_{2} \mathrm{O}_{5}$ hollow nanospheres with high surface energy (001) planes via ostwald ripening process, which owned high thermal stability, strong intensity of blue emission and efficiently split water under visible light irradiation.

Moreover, oxide of some p region elements also have photocatalytic activity, such as tin oxide $\left(\mathrm{SnO}_{2}\right)$, indium oxide $\left(\mathrm{In}_{2} \mathrm{O}_{3}\right)$, etc. Manjula et al. [52] utilize glucose as structure-directing agent to prepare porous tin oxide hollow spheres, which not only can photodegrade dye but also can be reused. The indium oxide hollow spheres gained by Li et al. [53] using emulsion vesicles as templates can photodecompose Rh B under ultraviolet light irradiation.

Surface modification still can be employed to enhance photocatalytic property of the aforementioned metal oxide hollow spheres. Ma et al. [54] doped tungsten oxide hollow spheres with silver-silver chloride to further improve their photocatalytic activity. Rahimi et al. [55] successfully prepared Ba-Cd-Sr-Ti doped ferroferric oxide $\left(\mathrm{Fe}_{3} \mathrm{O}_{4}\right)$ nanohollow spheres via a simple solvothermal method without any templates. The photocatalytic degradation rate of congo red solution by this nanohollow spheres under visible light irradiation can reach to 99.5\% when $\mathrm{pH}$ is 6 .

\subsection{Composite Metal Oxide}

When two or more kinds of semiconductor form a compound system with fixed microstructure, it can restrain the recombination of photogenerated electrons and holes to significantly improve the photocatalytic performance. Hence, composite metal oxide hollow spheres owned a more excellent photocatalytic activity than that of single metal oxide spheres. Composite metal oxide can be divided into metal oxide modification and non-metal oxide modification. 1) Two kinds of metal oxide can be mutually compounded, such as $\mathrm{ZnO}$ [56], $\mathrm{Fe}_{3} \mathrm{O}_{4}$ [57], zirconium oxide $\left(\mathrm{ZrO}_{2}\right)$ [58] composited with $\mathrm{TiO}_{2} ; \mathrm{In}_{2} \mathrm{O}_{3}$ [59], $\mathrm{SnO}_{2}$ [60], $\mathrm{CuO}$ [61], $\mathrm{GeO}_{2}$ [62] composited with $\mathrm{ZnO} ; \mathrm{Fe}_{2} \mathrm{O}_{3}$ composited with $\mathrm{MnO}$ [63]; bismuth oxide $\left(\mathrm{Bi}_{2} \mathrm{O}_{3}\right)$ composited with $\mathrm{WO}_{3}$ [64], $\mathrm{V}_{2} \mathrm{O}_{5}$ [65] [66], etc. When $\mathrm{WO}_{3}$ which has a low band gap combined with $\mathrm{TiO}_{2}$, it suppresses recombina-

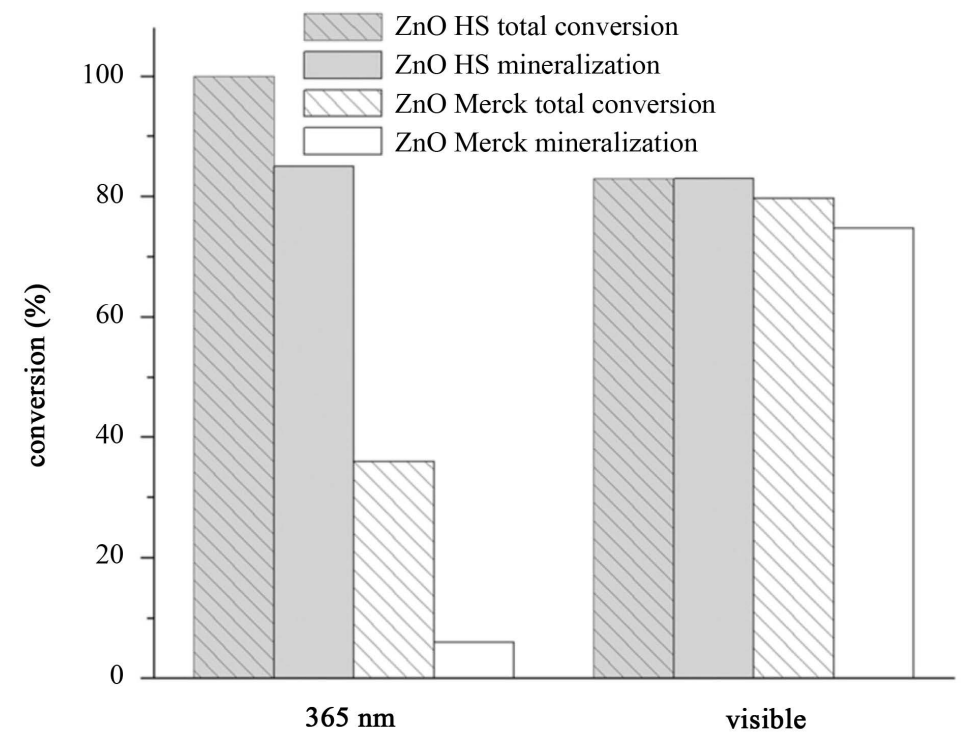

Figure 3. Effects of ZnO hollow sphere (HS) and commercial product (Merck) nature on degradation of phenol under same irradiation conditions [49]. 
tion of photogenerated electrons and holes on hollow spheres surface as well as broadens photo-responsive scope to enhance utilization rate for optical energy. Tian et al. [67] prepared hierarchical flower-like $\mathrm{Bi}_{2} \mathrm{MoO}_{6}$ hollow spheres via a solvothermal process in the presence of ethylene glycol, which can remove over $95 \% \mathrm{Rh} \mathrm{B}$ within $2 \mathrm{~h}$ under visible-light irradiation. Li et al. [68] prepared bismuth tungstate $\left(\mathrm{Bi}_{2} \mathrm{WO}_{6}\right)$ hollow spheres using polystyrene particles as the template, with $\mathrm{Bi}_{2} \mathrm{O}_{3}$ deposited on their surface and sequentially calcination to obtain double-shell $\mathrm{Bi}_{2} \mathrm{O}_{3}-\mathrm{Bi}_{2} \mathrm{WO}_{6}$ hollow spheres. The internal electric field of p-n junction formed by close contact between p-type $\mathrm{Bi}_{2} \mathrm{O}_{3}$ and n-type $\mathrm{Bi}_{2} \mathrm{WO}_{6}$ can speed up separation of photogenerated charge to boost photocatalytic performance, which makes this composite hollow spheres can completely decompose Rh B in 3 hours under visible light irradiation. $\mathrm{An}_{\mathrm{Ag}_{2}} \mathrm{ZnGeO}_{4}$ photocatalyst was obtained by Zhang and co-workers [69] via an ion-exchange reaction between amorphous $\mathrm{Zn}_{2} \mathrm{GeO}_{4}$ suspension and $\mathrm{Ag}$ ions solutions. The $\mathrm{Ag}_{2} \mathrm{ZnGeO}_{4}$ hollow sphere obtained through ostwald ripening process shows superior photocatalytic activity. 2) Few research has been focused on non-metal oxide modification. The composite between $\mathrm{TiO}_{2}$ and silicon oxide $\left(\mathrm{SiO}_{2}\right)$ is the relatively familiar one. $\mathrm{Li}$ et al. [70] prepared composite $\mathrm{SiO}_{2}-\mathrm{TiO}_{2}$ hollow spheres by coating colloid carbon microspheres template with $\mathrm{Si}$-doped $\mathrm{TiO}_{2}$ layer in a one-pot hydrothermal approach and sequentially calcination. The photodegradation rate of methylene blue solution under ultraviolet irradiation in 2 hours by the composite $\mathrm{SiO}_{2}-\mathrm{TiO}_{2}$ hollow spheres (80\%) exceeds that of $\mathrm{TiO}_{2}$ hollow spheres (54\%). In order to further improve photocatalytic activity of the above composite hollow spheres, measures such as surface noble metal deposition and element doping can be taken. Zhao et al. [71] prepared Ag modified hollow $\mathrm{SiO}_{2} / \mathrm{TiO}_{2}$ hybrid spheres through successively coating polystyrene spheres (PS) with $\mathrm{SiO}_{2}$ and $\mathrm{TiO}_{2}$ layer, evenly loading $\mathrm{Ag}$ nanoparticles by reducing silver nitrate onto surface of $\mathrm{TiO}_{2}$ layer, and then carrying out a calcination process to eliminate the template. The modified hollow spheres can efficiently degrade Rh B under both ultraviolet and visible light irradiation. Figure 4 shows UV-vis spectra of $\mathrm{Rh} \mathrm{B}$ with $\mathrm{Ag}$ modified hollow $\mathrm{SiO}_{2} / \mathrm{TiO}_{2}$ hybrid
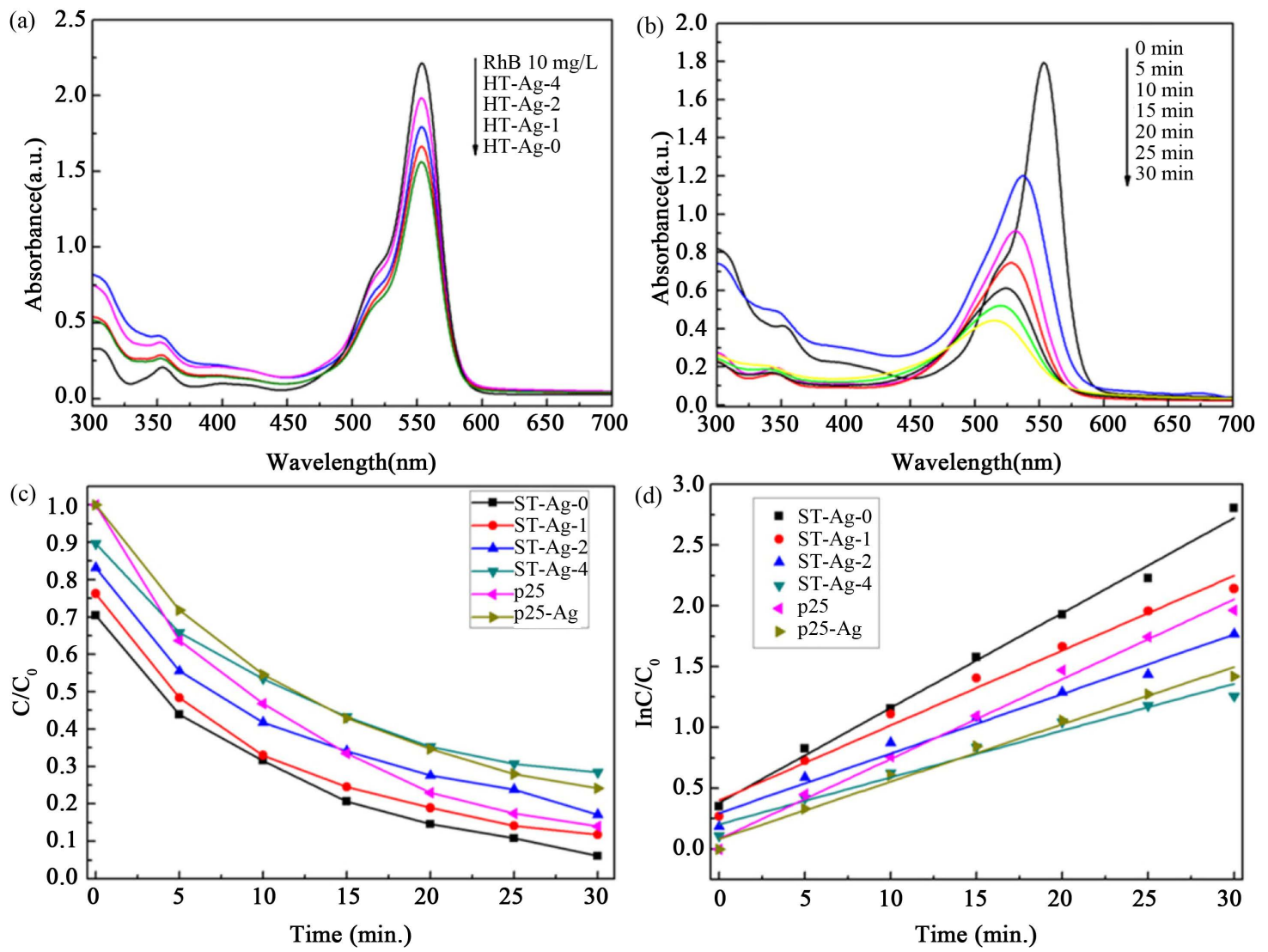

Figure 4. (a) UV-vis spectra of Rh $\mathrm{B}$ with Ag modified hollow $\mathrm{SiO}_{2} / \mathrm{TiO}_{2}$ hybrid spheres after 1 h dark absorption, photocatalytic degradation of Rh B under UV irradiation; (b) UV-vis spectra of the aqueous solutions of Rh B dye; (c) Photodegradation of the Rh B dye; (d) The corresponding pseudo-first-order kinetic rate plot [71]. 
spheres after $1 \mathrm{~h}$ dark absorption, photocatalytic degradation of Rh B under UV irradiation, UV-vis spectra of the aqueous solutions of Rh $\mathrm{B}$ dye, photodegradation plot of the $\mathrm{Rh} \mathrm{B}$ dye and the corresponding pseudofirst-order kinetic rate plot. Zhang et al. [72] prepared hollow cobalt, nitrogen co-doped $\mathrm{TiO}_{2} / \mathrm{SiO}_{2}$ microspheres using PS microspheres as templates, tetraethylorthosilicate and tetrabutyltitanate as precursors. The compound hollow spheres have a wide absorption wavelength to $600 \mathrm{~nm}$ and their photodegradation rate for $\mathrm{Rh} \mathrm{B}$ under visible light irradiation in 40 minute can reach to $98 \%$.

\section{Metal Sulfide Hollow Spheres}

\subsection{Single Metal Sulfide}

Metal sulfide as photocatalysts have attracted researchers' general attention in recent years. Cadmium sulfide (CdS), a typical semiconductor of II-VI group with the band gap at $2.42 \mathrm{eV}$, owns outstanding photocatalytic property. Li et al. [73] prepared hollow CdS nanospheres with a diameter of about $130 \mathrm{~nm}$ and controllable shell thickness through 1-butyl-3-methylimidazolium-bis(trifluoro-methylsulfonyl)-imide ionic liquids as the templates, polyvinylpyrrolidone adjusting the formation of spheres and hexamethylenetetramine regulating the size and shell thickness. The photodegradation rate for methylene blue by the hollow CdS spheres can achieve 81\% under ultraviolet irradiation in 80 minutes. Elements doping can effectively overcome its instability for light. Luo and co-workers [74] prepared nickel ion $\left(\mathrm{Ni}^{2+}\right)$ doped CdS hollow spheres via a template-free one-pot method. The obtained $1.2 \mathrm{~mol} \%$ Ni-doped CdS hollow spheres can completely decompose Rh B under visible light $(\lambda>420 \mathrm{~nm})$ in 35 minutes and the degradation rate keeps over $98 \%$ after using 4 times. Figure 5 shows the photogagradation plot for Rh B under visible light of Ni-doped CdS hollow spheres.

Besides, zinc sulfide $(\mathrm{ZnS})$, indium sulfide $\left(\mathrm{In}_{2} \mathrm{~S}_{3}\right)$ and copper sulfide (CuS) also have a certain degree of photocatalytic property. Yu and co-workers [75] prepared hexagonal wurtzite ZnS hollow spheres via one-pot template-free hydrothermal route using zinc acetate dehydrate and thiourea as raw materials. The ZnS hollow sphere shows strong absorption less than $365 \mathrm{~nm}$. Zhang et al. [76] successfully synthesized Bi-doped ZnS hollow spheres (BZ) with enhanced ultraviolet and visible-light photocatalytic activity because of the formation of an isolated state originating from $\mathrm{Bi}$ 6s above the top of the valence band of $\mathrm{ZnS}$ and the electron excitation from $\mathrm{Bi}$ 6s state to the conduction band occurred under visible light irradiation. Under the optimal content of Bi dopant ( $\mathrm{R}=0.3$, which is defined as the nominal atomic ratio of $\mathrm{Bi}$ to $\mathrm{Zn}$ ), that is 0.3 at\%, the hydrogen production rate is 1030 and $134 \mu \mathrm{mol} \cdot \mathrm{h}^{-1} \cdot \mathrm{g}^{-1}$ under UV and visible-light irradiation, respectively.

Rengaraj et al. [77] obtained tetragonal porous $\mathrm{In}_{2} \mathrm{~S}_{3}$ hollow spheres composed of two-dimensional nanosheets and nanorods via a one-step solvothermal method using thiosemic arbazide as both sulfur source and capping ligand. The above-mentioned hollow spheres can photodegrade 30\% percentage of methyl blue solution

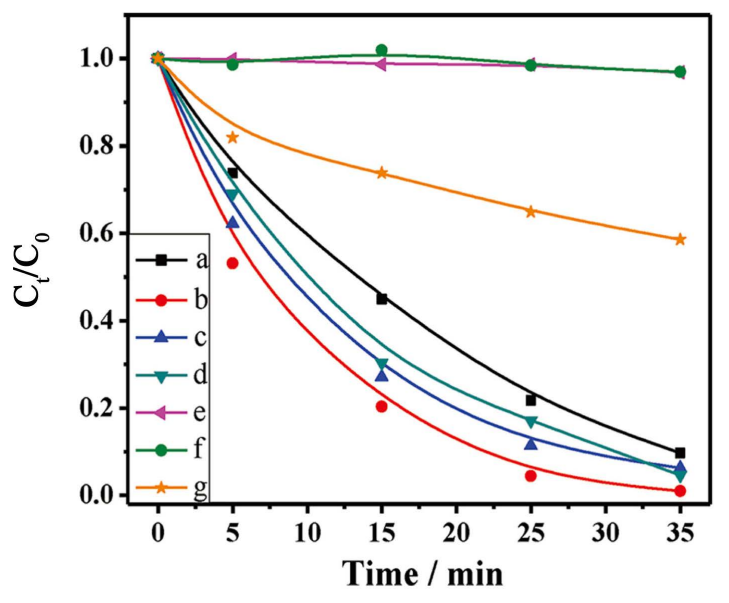

Figure 5. $\mathrm{C}_{\mathrm{t}} / \mathrm{C}_{0}$ versus time curves of Rh $\mathrm{B}$ photodegradation under visible-light $(\lambda>420 \mathrm{~nm}$ ) irradiation over (a) CdS; (b) 1.2 mol\% Ni-doped CdS; (c) 3 mol\% Ni-doped CdS; (d) 5 mol\% Ni-doped CdS; (e) Catalyst free; (f) Light off; and (g) Degussa P25 [74]. 
under visible light irradiation in 3 hours. Meng et al. [78] prepared hierarchical flower-like CuS hollow nanospheres via a solvothermal approach. The CuS hollow nanospheres obtained can photodegrade $\mathrm{Rh} B$ and 2,4-dichlorophenol aqueous solution because of the synergistic effect of surface hierarchical structure with large surface area, porous hollow sphere structure and high visible light utilization.

\subsection{Composite Metal Sulfide}

Compared to single metal sulfide, composite metal sulfide has more superior photocatalytic activity and broaden light responsive scope. However, until now few studies of composite metal sulfide hollow spheres concentrated on phohocatalytic realm. The way to get composite metal sulfide hollow spheres is mainly by simple coupling and doping. Zhu et al. [79] prepared composite ( $\mathrm{Ag}, \mathrm{Cu})_{2} \mathrm{~S}$ hollow spheres with cation exchange method using spherical aggregates of $\mathrm{CuS}$ nanoparticles as templates. The composite $(\mathrm{Ag}, \mathrm{Cu})_{2} \mathrm{~S}$ hollow spheres have strong absorption at ultraviolet light scope from $200 \mathrm{~nm}$ to $500 \mathrm{~nm}$ and infrared light scope from $1000 \mathrm{~nm}$ to $2500 \mathrm{~nm}$, but weak absorption at visible light scope from $500 \mathrm{~nm}$ to $800 \mathrm{~nm}$, which makes selective light absorption come true. Yu et al. [80] prepared composite CuS-ZnS hollow nanospheres by an ion-exchange method using ZnS solid spheres as a precursor and copper nitrate as raw materials. The photodegradation rate for Rh B by the composite hollow nanospheres is obviously higher than that of $\mathrm{CuS}$ and $\mathrm{ZnS}$ solid spheres. Bhirud et al. [81] prepared $\mathrm{CdIn}_{2} \mathrm{~S}_{4}$ hollow spheres assembled by nanoparticles with a flower like morphology using cadmium nitrate tetrahydrate, indium nitrate trihydrate, thiourea and cetyl trimethyl ammonium bromide as raw materials. The rate of hydrogen production from $\mathrm{H}_{2} \mathrm{~S}$ photodecomposition for $\mathrm{CdIn}_{2} \mathrm{~S}_{4}$ hollow spheres is $3171 \mu \mathrm{mol} \cdot \mathrm{h}^{-1}$, which is almost three fold enhancement than the highest rate of hydrogen production from normal bulk CdS $\left(847 \mu \mathrm{mol} \cdot \mathrm{h}^{-1}\right)$. Xing and co-workers [82] prepared a type of ternary $\mathrm{Ag} / \mathrm{Ag}_{2} \mathrm{~S} / \mathrm{Ag}_{3} \mathrm{CuS}_{2}$ hollow microspheres with $\mathrm{Cu}_{7} \mathrm{~S}_{4}$ hollow submicrospheres as the template, the photocatalytic activity of which was higher than those of $\mathrm{Ag} / \mathrm{Ag}_{2} \mathrm{~S}, \mathrm{Cu}_{2} \mathrm{O}, \mathrm{Cu}_{7} \mathrm{~S}_{4}$ and P25 for the photodegradation of MO under visible light irradiation. Superoxide radicals and holes were confirmed to be the main reactive species for $\mathrm{MO}$ degradation through radical scavenger experiments. Figure 6 shows photogagradation plot for $\mathrm{MO}$ under visible light of the as-obtained $\mathrm{Ag} / \mathrm{Ag}_{2} \mathrm{~S} /$ $\mathrm{Ag}_{3} \mathrm{CuS}_{2}$ hollow microspheres.

\section{Application}

\subsection{Sewage Treatment}

Organic pollutants durably presented in sewage often have reducibility. Consequently, inorganic hollow sphere photocatalysts can randomly oxidize organic pollutants by photo-generated holes and hydroxyl to carbon dioxide $\left(\mathrm{CO}_{2}\right)$, water and other nontoxic inorganic substances to purify water, as well as avoiding secondary water pollution. At present, photocatalytic technology can effectively degrade halogenated aliphatic hydrocarbon, dye, nitroaromatic compounds, polycyclic aromatic hydrocarbon, heterocyclic compounds, hydrocarbon, phenols, surfactants, pesticides and so on. For example, nitrogen doped $\mathrm{TiO}_{2}$ hollow spheres can decompose bisphenol A [83], carbon, nitrogen co-doped $\mathrm{TiO}_{2}$ hollow spheres can remove dye X-3B [84], copper ion doped $\mathrm{TiO}_{2}$ hollow spheres can degrade chlorotetracycline [85], zirconium oxide doped $\mathrm{TiO}_{2}$ hollow spheres can decompose $\mathrm{Rh} \mathrm{B}$ [58], bismuth molybdate hollow spheres can decompose phenol [86] and $\mathrm{Zn}_{2} \mathrm{GeO}_{4}$ hollow spheres can degrade antibiotic metronidazole [87]. While inorganic hollow spheres as water purification material have achieved great progress, it also exists limitations such as unable to efficiently resolve high concentration wastewater and difficult to recycle for powder catalyst.

\subsection{Air Purification}

Due to the vast application of organic materials and continuous off-gas emissions from automobile, there is a large amount of poisonous organic gas and nitrogen oxides suspending in our breathing air. Air purification by photocatalysts can operate at normal temperature and pressure, do no harm to environmental and human body, costs little, completely decompose organics. Dong et al. [88] prepared hierarchical (BiO) ${ }_{2} \mathrm{CO}_{3}$ hollow microspheres which can be reused as NO removal material in indoor air. The indium vanadate hollow spheres prepared by Ai et al. [89] can oxidize NO to nitric acid under visible light and maintain their photocatalytic ratio after reused. Ikeda et al. [90] encapsulates $\mathrm{TiO}_{2}$ into a hollow $\mathrm{SiO}_{2}$ shell to attain a type of composite material, which can decompose gas-phase acetone and isopropanol into $\mathrm{CO}_{2}$. Nevertheless, absence of applied research on 

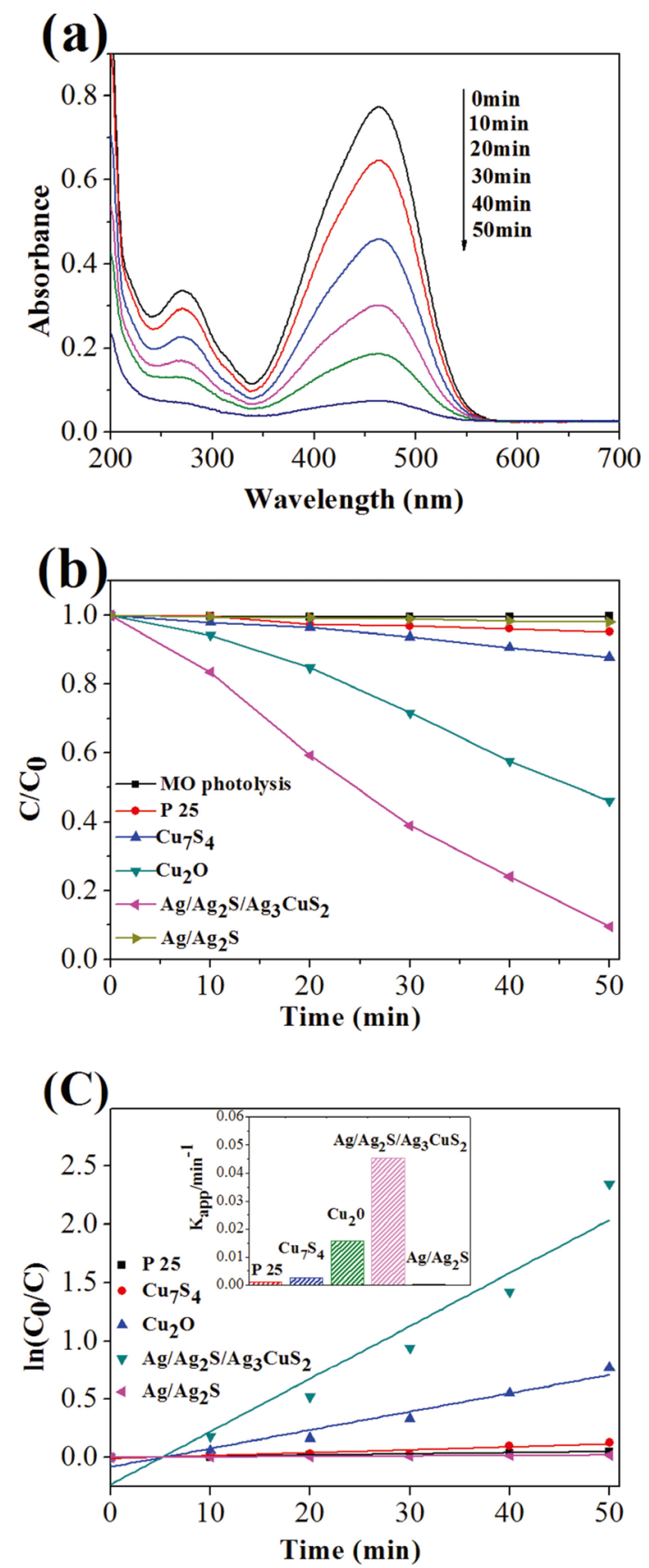

Figure 6. (a) UV-visible absorption spectra of degradation of $\mathrm{MO}$ by $\mathrm{Ag} / \mathrm{Ag}_{2} \mathrm{~S} / \mathrm{Ag}_{3} \mathrm{CuS}_{2}$ under visible light $(\lambda>420 \mathrm{~nm})$; (b) photocatalytic degradation of MO over different photocatalysts; (c) Linear transformation $\ln C_{0} / C=$ Kappt of the kinetic curves of MO degradation over different photocatalysts. The inset shows the Kapp for MO degradation over different photocatalysts [82].

air-handling equipment gives rise to the unrealizable industrialization of air purification by nanosize photocatalysts.

\subsection{Hydrogen Production}

Hydrogen gas is a kind of clean energy sources with a high combustion value, superior efficiency and environmental friendly. The hydrogen production chiefly depends on coal and natural gas so far, which could aggravate 
consumption of nonrenewable resources and environmental pollution. The most ideal way to settle down the problem is to transfer solar energy into hydrogen energy with photocatalyst using renewable substance as raw materials such as water and biomass. The hierarchical $\mathrm{Sn}_{2} \mathrm{Nb}_{2} \mathrm{O}_{7}$ hollow spheres synthesized by Zhou et al. shows a superior visible-light-driven photocatalytic $\mathrm{H}_{2}$ production activity $\left(3 \mu \mathrm{mol} \cdot \mathrm{h}^{-1}\right)$, which is about 4 times higher than that of the bulk $\mathrm{Sn}_{2} \mathrm{Nb}_{2} \mathrm{O}_{7}$ sample prepared by a conventional high temperature solid state reaction method [91]. Zhang [92] and co-workers prepared composite CdS- $\mathrm{TiO}_{2}$ hollow sphere by coupling $\mathrm{TiO}_{2}$ to $\mathrm{CdS}$ which had a conduction band potential more negative than that of $\mathrm{H}^{+} / \mathrm{H}_{2}$ via a hydrothermal process, second step impregnation method and sol-gel method in sequence. The hydrogen production rate by the composite hollow spheres from water under ultraviolet light irradiation in one hour is $0.81 \mathrm{ml} / \mathrm{g}$. After that, they prepared NiOCdS hollow spheres with p-n junction, the hydrogen production rate by which under ultraviolet light irradiation in one hour $(1.81 \mathrm{ml} / \mathrm{g})$ precede the common composite $\mathrm{CdS}-\mathrm{TiO}_{2}$ hollow spheres [93]. The reason is that interior electric field of p-n junction boosting transport rate of photo-production electronics. While great progresses have been achieved in hydrogen production by photocatalysts until now, it fails to meet practical applications for the low efficiency of directly water splitting.

\section{4. $\mathrm{CO}_{2}$ Reduction}

Greenhouse gas $\mathrm{CO}_{2}$ is a major cause to global warming. It is also a kind of potential carbon resources. Hence, effective control and utilization of $\mathrm{CO}_{2}$ becomes research focus. Present emission reduction technology requires numerous energy and exists potential safety problems in application. In the process of constant exploring emission reduction technology, it has been found that photogenerated electronics can change $\mathrm{CO}_{2}$ to organic compounds with high application value such as methane and methanol. Tu et al. [94] prepared hollow spheres consisting of alternating $\mathrm{Ti}_{0.91} \mathrm{O}_{2}$ nanosheets and graphene nanosheets with polymer beads as sacrificial templates and via a microwave irradiation technique. The ultrathin $\mathrm{Ti}_{0.91} \mathrm{O}_{2}$ nanosheets allow charge carriers to move rapidly onto the surface to take part in the photoreduction reaction and the alternating compact stacking structure allow the photogenerated electron to transfer fast from $\mathrm{Ti}_{0.91} \mathrm{O}_{2}$ nanosheets to graphene nanosheets to extend lifetime of the charge carriers. The photocatalytic activity of the hollow spheres is 9 times higher than P25. It can reduce $\mathrm{CO}_{2}$ to carbonic oxide and methane. Photocatalytic reduction for $\mathrm{CO}_{2}$ operates at normal temperature and pressure, directly ultilizes solar light with no energy consumption, does no harm to environment, is the most promising conversion method.

\subsection{Other Application}

Photogenerated holes and electronics can directly react with compounds which deactive cytoderm, cytomembrane and cell leading to the death of bacterium. So, photocatalysts can be used as a new type of antibacterial materials. Feng et al. [95] prepared Ag-doped $\mathrm{TiO}_{2}$ hollow spheres by hydrothermal precipitation method using carbon spheres as the templates. $\mathrm{TiO}_{2}$ hollow sphere doping $9.4 \mathrm{~mol} \%$ Ag has excellent antibacterial activities against scherichia coli, staphylococcus aurels and candida albicans at room temperature. Furthermore, hollow spheres with photocatalytic properties can be photoelectric detector [96].

\section{Outlook}

Inorganic hollow spheres show their excellent performance in photocatalytic area, which belongs to their large specific surface area, controllable structure and their own special optical, electrical, magnetic properties. They can be widely applied in sewage treatment, hydrogen production, air purification and other field. Metal oxide, metal sulfide and composite hollow spheres formed by metal oxide or sulfide have successfully prepared and primarily improve their photocatalytic property by controlling surface morphology and doping various other semiconductors. However, owing to the limitations of synthetic method, there exist some drawbacks including poor structure controllability, uneven shell thickness and broad particle size distribution, which are adverse to photocatalytic activity. Therefore, inorganic hollow spheres with well structure and property controllability remain to be one of the principal development trends in photocatalytic field. On the other hand, various types of inorganic hollow spheres own photocatalytic property, but the photodegradation efficiency is low. Rare earth elements possess unique $\mathrm{f}$ electronic configuration and abundant storage. So, hollow spheres composed of rare earth elements will be one of the research focuses in photocatalytic area. 


\section{Acknowledgements}

The support from National Natural Science Foundation of China (No. 21106084), Shanghai Science and Research Innovation Foundation (No. 14zz164) and Shanghai Rising-Star Program (14QA143300) was appreciated.

\section{References}

[1] Hu, J., Chen, M., Fang, X. and Wu, L. (2011) Fabrication and Application of Inorganic Hollow Spheres. Chemical Society Reviews, 40, 5472-5491. http://dx.doi.org/10.1039/c1cs15103g

[2] Gao, R., Chen, M., Li, W., Zhou, S. and Wu, L. (2013) Facile Fabrication and Some Specific Properties of Polymeric/ Inorganic Bilayer Hybrid Hollow Spheres. Journal of Materials Chemistry A, 1, 2183-2191. http://dx.doi.org/10.1039/c2ta00837h

[3] Zhu, B.T., Wang, Z., Ding, S., Chen, J.S. and Lou, X.W. (2011) Hierarchical Nickel Sulfide Hollow Spheres for High Performance Supercapacitors. RSC Advances, 1, 397-400. http://dx.doi.org/10.1039/c1ra00240f

[4] Guan, J., Mou, F., Sun, Z. and Shi, W. (2010) Preparation of Hollow Spheres with Controllable Interior Structures by Heterogeneous Contraction. Chemical Communications, 46, 6605-6607. http://dx.doi.org/10.1039/c0cc01044h

[5] Li, P., Fan, H., Cai, Y. and Xu, M. (2014) Zn-Doped $\operatorname{In}_{2} \mathrm{O}_{3}$ Hollow Spheres: Mild Solution Reaction Synthesis and Enhanced $\mathrm{Cl}_{2}$ Sensing Performance. CrystEngComm, 16, 2715-2722. http://dx.doi.org/10.1039/c3ce42325e

[6] Xu, S., Hessel, C.M., Ren, H., Yu, R.B., Jin, Q., Yang, M., et al. (2014) $\alpha-\mathrm{Fe}_{2} \mathrm{O}_{3}$ Multi-Shelled Hollow Microspheres for Lithium Ion Battery Anodes with Superior Capacity and Charge Retention. Energy \& Environmental Science, 7, 632-637. http://dx.doi.org/10.1039/c3ee43319f

[7] Tian, W., Zhang, C., Zhai, T.Y., Li, S.L., Wang, X., Liao, M.Y., et al. (2013) Flexible $\mathrm{SnO}_{2}$ Hollow Nanosphere Film Based High-Performance Ultraviolet Photodetector. Chemical Communications, 49, 3739-3741. http://dx.doi.org/10.1039/c3cc39273b

[8] Cong, H., Wang, Y., Yu, B., Wang, J. and Jiao, M. (2014) Synthesis of Anisotropic TiO ${ }_{2}$ Hollow Microspheres Using Cave Particles as Templates and Application in Water Treatment. New Journal of Chemistry, 38. 2564-2568. http://dx.doi.org/10.1039/c3nj01302b

[9] Xue, C., Wang, T., Yang, G., Yang, B. and Ding, S. (2014) A Facile Strategy for the Synthesis of Hierarchical TiO ${ }_{2}$ CdS Hollow Sphere Heterostructures with Excellent Visible Light Activity. Journal of Materials Chemistry A, 2, 76747679. http://dx.doi.org/10.1039/c4ta01190b

[10] Wu, L., Feng, H., Liu, M., Zhang, K. and Li, J. (2013) Graphene-Based Hollow Spheres as Efficient Electrocatalysts for Oxygen Reduction. Nanoscale, 5, 10839-10843. http://dx.doi.org/10.1039/c3nr03794k

[11] Li, R., Li, L., Han, Y., Gai, S., He, F. and Yang, P. (2014) Core-Shell Structured $\mathrm{Gd}_{2} \mathrm{O}_{3}: \mathrm{Ln} @ m$ SiO 2 Hollow Nanospheres: Synthesis, Photoluminescence and Drug Release Properties. Journal of Materials Chemistry B, 2, 2127-2135. http://dx.doi.org/10.1039/c3tb21718c

[12] Sun, Z., Liao, T., Kim, J.G., Liu, K., Jiang, L., Kim, J.H., et al. (2013) Architecture Designed ZnO Hollow Microspheres with Wide-Range Visible-Light Photoresponses. Journal of Materials Chemistry C, 1, 6924-6929. http://dx.doi.org/10.1039/c3tc31649a

[13] Ye, M., Chen, Z., Wang, W., Shen, J. and Ma, J. (2010) Hydrothermal Synthesis of $\mathrm{TiO}_{2}$ Hollow Microspheres for the Photocatalytic Degradation of 4-Chloronitrobenzene. Journal of Hazardous Materials, 184, 612-619. http://dx.doi.org/10.1016/j.jhazmat.2010.08.080

[14] Li, G., Zhang, H., Lan, J., Li, J., Chen, Q., Liu, J., et al. (2013) Hierarchical Hollow TiO ${ }_{2}$ Spheres: Facile Synthesis and Improved Visible-Light Photocatalytic Activity. Dalton Transactions, 42, 8541-8544. http://dx.doi.org/10.1039/c3dt50503k

[15] Gong, X.Q. and Selloni, A. (2005) Reactivity of Anatase $\mathrm{TiO}_{2}$ Nanoparticles: The Role of the Minority (001) Surface. Journal of Physical Chemistry B, 109, 19560-19562. http://dx.doi.org/10.1021/jp055311g

[16] Nakamura, R., Ohashi, N., Imanishi, A., Osawa, T., Matsumoto, Y., Koinuma, H., et al. (2005) Crystal-Face Dependences of Surface Band Edges and Hole Reactivity, Revealed by Preparation of Essentially Atomically Smooth and Stable (110) and (100) n- $\mathrm{TiO}_{2}$ (Rutile) Surfaces. Journal of Physical Chemistry B, 109, 1648-1651. http://dx.doi.org/10.1021/jp044710t

[17] Ong, W.J., Tan, L.L., Chai, S.P., Yong, S.T. and Mohamed, A.R. (2014) Highly Reactive $\{001\}$ Facets of TiO $_{2}$-Based Composites: Synthesis, Formation Mechanism and Characterization. Nanoscale, 6, 1946-2008. http://dx.doi.org/10.1039/c3nr04655a

[18] Wang, X., He, H., Chen, Y., Zhao, J. and Zhang, X. (2012) Anatase $\mathrm{TiO}_{2}$ Hollow Microspheres with Exposed \{001\} 
Facets: Facile Synthesis and Enhanced Photocatalysis. Applied Surface Science, 258, 5863-5868. http://dx.doi.org/10.1016/j.apsusc.2012.02.117

[19] Jiao, Y., Peng, C., Guo, F., Bao, Z., Yang, J., Schmidt-Mende, L., et al. (2011) Facile Synthesis and Photocatalysis of Size-Distributed $\mathrm{TiO}_{2}$ Hollow Spheres Consisting of $\{116\}$ Plane-Oriented Nanocrystallites. The Journal of Physical Chemistry C, 115, 6405-6409. http://dx.doi.org/10.1021/jp200491u

[20] Li, S., Chen, J., Zheng, F., Li, Y. and Huang, F. (2013) Synthesis of the Double-Shell Anatase-Rutile $\mathrm{TiO}_{2} \mathrm{Hollow}$ Spheres with Enhanced Photocatalytic Activity. Nanoscale, 5, 12150-12155. http://dx.doi.org/10.1039/c3nr04043g

[21] Zeng, Y., Wang, X., Wang, H., Dong, Y., Ma, Y. and Yao, J. (2010) Multi-Shelled Titania Hollow Spheres Fabricated by a Hard Template Strategy: Enhanced Photocatalytic Activity. Chemical Communications, 46, 4312-4314. http://dx.doi.org/10.1039/c0cc00706d

[22] Tao, Y.G., Xu, Y., Pan, J., Gu, H., Qin, C. and Zhou, P. (2012) Glycine Assisted Synthesis of Flower-Like TiO ${ }_{2}$ Hie- $^{-}$ rarchical Spheres and Its Application in Photocatalysis. Materials Science and Engineering: B, 177, 1664-1671. http://dx.doi.org/10.1016/j.mseb.2012.08.010

[23] Liu, J., Chang, L., Wang, J., Zhu, M. and Zhang, W. (2010) A Facile One-Step Approach to Visible-Light-Sensitive Vanadium-Doped $\mathrm{TiO}_{2}$ Hollow Microspheres. Materials Science and Engineering: B, 172, 142-145. http://dx.doi.org/10.1016/j.mseb.2010.04.037

[24] Feng, X., Yang, O., Yang, L., Guang, Q. and Liu, Y.L. (2010) Preparation of Pt-Doped $\mathrm{TiO}_{2}$ Hollow Spheres by Hydrothermal Precipitation and Their Photocatalytic Activities in Rh B Degradation. Journal of Jinan University, 31, 495499.

[25] Wang, C., Ao, Y., Wang, P., Hou, J., Qian, J. and Zhang, S. (2010) Preparation, Characterization, Photocatalytic Properties of Titania Hollow Sphere Doped with Cerium. Journal of Hazardous Materials, 178, 517-521. http://dx.doi.org/10.1016/j.jhazmat.2010.01.111

[26] Wang, C., Ao, Y., Wang, P., Hou, J. and Qian, J. (2010) Preparation, Characterization and Photocatalytic Activity of the Neodymium-Doped $\mathrm{TiO}_{2}$ Hollow Spheres. Applied Surface Science, 257, 227-231. http://dx.doi.org/10.1016/j.apsusc.2010.06.071

[27] Xu, J., Ao, Y. and Chen, M. (2009) Preparation of B-Doped Titania Hollow Sphere and Its Photocatalytic Activity under Visible Light. Materials Letters, 63, 2442-2444. http://dx.doi.org/10.1016/j.matlet.2009.08.031

[28] Ao, Y., Xu, J., Fu, D. and Yuan, C. (2009) A Simple Method to Prepare N-Doped Titania Hollow Spheres with High Photocatalytic Activity under Visible Light. Journal of Hazardous Materials, 167, 413-417. http://dx.doi.org/10.1016/j.jhazmat.2008.12.139

[29] Ao, Y., Xu, J., Zhang, S. and Fu, D. (2010) A One-Pot Method to Prepare N-Doped Titania Hollow Spheres with High Photocatalytic Activity under Visible Light. Applied Surface Science, 256, 2754-2758. http://dx.doi.org/10.1016/j.apsusc.2009.11.023

[30] Zhuang, J., Tian, Q., Zhou, H., Liu, Q., Liu, P. and Zhong, H. (2012) Hierarchical Porous TiO $@$ @C Hollow Microspheres: One-Pot Synthesis and Enhanced Visible-Light Photocatalysis. Journal of Materials Chemistry, 22, 70367042. http://dx.doi.org/10.1039/c2jm16924j

[31] Shi, J.W., Chen, J.W., Cui, H.J., Fu, M.L., Luo, H.Y., Xu, B., et al. (2012) One Template Approach to Synthesize CDoped Titania Hollow Spheres with High Visible-Light Photocatalytic Activity. Chemical Engineering Journal, 195196, 226-232. http://dx.doi.org/10.1016/j.cej.2012.04.095

[32] Zhou, J.K., Lv, L., Yu, J., Li, H.L., Guo, P.Z., Sun, H., et al. (2008) Synthesis of Self-Organized Polycrystalline FDoped $\mathrm{TiO}_{2}$ Hollow Microspheres and Their Photocatalytic Activity under Visible Light. The Journal of Physical Chemistry C, 112, 5316-5321. http://dx.doi.org/10.1021/jp709615x

[33] Yu, J. and Shi, L. (2010) One-Pot Hydrothermal Synthesis and Enhanced Photocatalytic Activity of Trifluoroacetic Acid Modified $\mathrm{TiO}_{2}$ Hollow Microspheres. Journal of Molecular Catalysis A: Chemical, 326, 8-14. http://dx.doi.org/10.1016/j.molcata.2010.04.016

[34] Wang, C., Ao, Y., Wang, P., Hou, J. and Qian, J. (2011) Preparation of Cerium and Nitrogen Co-Doped Titania Hollow Spheres with Enhanced Visible Light Photocatalytic Performance. Powder Technology, 210, 203-207. http://dx.doi.org/10.1016/j.powtec.2011.03.015

[35] Lu, J., Su, F., Huang, Z., Zhang, C., Liu, Y., Ma, X., et al. (2013) N-Doped Ag/TiO ${ }_{2}$ Hollow Spheres for Highly Efficient Photocatalysis under Visible-Light Irradiation. RSC Advances, 3, 720-724. http://dx.doi.org/10.1039/c2ra22713d

[36] Wang, S., Qian, H., Hu, Y., Dai, W., Zhong, Y., Chen, J., et al. (2013) Facile One-Pot Synthesis of Uniform TiO $2^{-}$Ag Hybrid Hollow Spheres with Enhanced Photocatalytic Activity. Dalton Transactions, 42, 1122-1128. http://dx.doi.org/10.1039/c2dt32040a

[37] Xiang, Q., Yu, J., Cheng, B. and Ong, H.C. (2010) Microwave-Hydrothermal Preparation and Visible-Light Photoactivity of Plasmonic Photocatalyst Ag- $\mathrm{TiO}_{2}$ Nanocomposite Hollow Spheres. Chemistry: An Asian Journal, 5, 1466-1474. 
http://dx.doi.org/10.1002/asia.200900695

[38] Jiang, Z., Zhu, J., Liu, D., Wei, W., Xie, J. and Chen, M. (2014) In Situ Synthesis of Bimetallic Ag/Pt Loaded SingleCrystalline Anatase $\mathrm{TiO}_{2}$ Hollow Nano-Hemispheres and Their Improved Photocatalytic Properties. CrystEngComm, 16, 2384-2394. http://dx.doi.org/10.1039/c3ce41949e

[39] Fei, H.L., Zhou, H.J., Wang, J.G., Sun, P.C., Ding, D.T. and Chen, T.H. (2008) Synthesis of Hollow V $\mathrm{O}_{5}$ Microspheres and Application to Photocatalysis. Solid State Sciences, 10, 1276-1284. http://dx.doi.org/10.1016/j.solidstatesciences.2007.12.026

[40] Duan, Z.Y. and Chen, Y.C. (2010) Hydrothermal Preparation for Self-Assembled $\gamma-\mathrm{MnO}_{2}$ Hollow Spheres and Their Photocatalytic Activity. Journal of Anqing Teachers College (Natural Science), 16, 88-91. http://dx.doi.org/10.3969/j.issn.1007-4260.2010.02.026

[41] Song, X.F. and Gao, L. (2008) Facile Synthesis and Hierarchical Assembly of Hollow Nickel Oxide Architectures Bearing Enhanced Photocatalytic Properties. Journal of Physical Chemistry C, 112, 15299-15305. http://dx.doi.org/10.1021/jp804921g

[42] Guo, G.L. and Huang, J.H. (2011) $\mathrm{Ta}_{2} \mathrm{O}_{5}$ Hollow Sphere: Fabrication and Photocatalytic Activity. Chinese Journal of Inorganic Chemistry, 27, 214-218. http://d.wanfangdata.com.cn/Periodical_wjhxxb201102002.aspx

[43] Xu, J.S. and Zhu, Y.J. (2011) $\alpha-\mathrm{Fe}_{2} \mathrm{O}_{3}$ Hierarchically Hollow Microspheres Self-Assembled with Nanosheets: Surfactant-Free Solvothermal Synthesis, Magnetic and Photocatalytic Properties. CrystEngComm, 13, 5162-5169. http://dx.doi.org/10.1039/c1ce05252g

[44] Yu, Y., Zhang, L., Wang, J., Yang, Z., Long, M., Hu, N., et al. (2012) Preparation of Hollow Porous Cu $\mathrm{C}_{2} \mathrm{O}$ Microspheres and Photocatalytic Activity under Visible Light Irradiation. Nanoscale Research Letters, 7, 347-353.

[45] Huang, J., Xu, X., Gu, C., Fu, G., Wang, W. and Liu, J. (2012) Flower-Like and Hollow Sphere-Like $\mathrm{WO}_{3}$ Porous Nanostructures: Selective Synthesis and Their Photocatalysis Property. Materials Research Bulletin, 47, 3224-3232. http://dx.doi.org/10.1016/j.materresbull.2012.08.009

[46] Yu, J., Qi, L., Cheng, B. and Zhao, X. (2008) Effect of Calcination Temperatures on Microstructures and Photocatalytic Activity of Tungsten Trioxide Hollow Microspheres. Journal of Hazardous Materials, 160, 621-628. http://dx.doi.org/10.1016/j.jhazmat.2008.03.047

[47] Yu, J.G. and Yu, X.X. (2008) Hydrothermal Synthesis and Photocatalytic Activity of Zinc Oxide Hollow Spheres. Environmental Science \&Technology, 42, 4902-4907. http://dx.doi.org/10.1021/es800036n

[48] Khoa, N.T., Kim, S.W., Thuan, D.V., Yoo, D.H., Kim, E.J. and Hahn, S.H. (2014) Hydrothermally Controlled ZnO Nanosheet Self-Assembled Hollow Spheres/Hierarchical Aggregates and Their Photocatalytic Activities. CrystEngComm, 16, 1344-1350. http://dx.doi.org/10.1039/c3ce41763h

[49] Patrinoiu, G., Tudose, M., Calderón-Moreno, J.M., Birjega, R., Budrugeac, P., Ene, R., et al. (2012) A Green Chemical Approach to the Synthesis of Photoluminescent ZnO Hollow Spheres with Enhanced Photocatalytic Properties. Journal of Solid State Chemistry, 186, 17-22. http://dx.doi.org/10.1016/j.jssc.2011.11.024

[50] Cao, S.W. and Zhu, Y.J. (2008) Hierarchically Nanostructured $\alpha-\mathrm{Fe}_{2} \mathrm{O}_{3}$ Hollow Spheres: Preparation, Growth Mechanism, Photocatalytic Property and Application in Water Treatment. Journal of Physical Chemistry C, 112, 6253-6257. http://dx.doi.org/10.1021/jp8000465

[51] Li, L., Deng, J., Yu, R., Chen, J., Wang, Z. and Xing, X. (2013) Niobium Pentoxide Hollow Nanospheres with Enhanced Visible Light Photocatalytic Activity. Journal of Materials Chemistry A, 1, 11894-11900. http://dx.doi.org/10.1039/c3ta12599h

[52] Manjula, P., Boppella, R. and Manorama, S.V. (2012) A Facile and Green Approach for the Controlled Synthesis of Porous $\mathrm{SnO}_{2}$ Nanospheres: Application as an Efficient Photocatalyst and an Excellent Gas Sensing Material. ACS Applied Materials \& Interfaces, 4, 6252-6260. http://dx.doi.org/10.1021/am301840s

[53] Li, B.X., Xie, Y., Jing, M., Rong, G., Tang, Y. and Zhang, G. (2006) $\operatorname{In}_{2} \mathrm{O}_{3}$ Hollow Microspheres: Sythesis from Designed $\mathrm{In}(\mathrm{OH})_{3}$ Precursors and Applications in Gas Sensors and Photocatalysis. Langmuir, 22, 9380-9385. http://dx.doi.org/10.1021/la061844k

[54] Ma, B., Guo, J., Dai, W.L. and Fan, K. (2012) Ag-AgCl/ $/ \mathrm{WO}_{3}$ Hollow Sphere with Flower-Like Structure and Superior Visible Photocatalytic Activity. Applied Catalysis B: Environmental, 123-124, 193-199. http://dx.doi.org/10.1016/j.apcatb.2012.04.029

[55] Rahimi, R., Tadjarodi, A., Rabbani, M., Kerdari, H. and Imani, M. (2012) Preparation, Characterization and Photocatalytic Properties of Ba-Cd-Sr-Ti Doped $\mathrm{Fe}_{3} \mathrm{O}_{4}$ Nanohollow Spheres on Removal of Congo Red under Visible-Light Irradiation. Journal of Superconductivity and Novel Magnetism, 26, 219-228. http://dx.doi.org/10.1007/s10948-012-1716-9

[56] Agrawal, M., Gupta, S., Pich, A., Zafeiropoulos, N.E. and Stamm, M. (2009) A Facile Approach to Fabrication of ZnO-TiO ${ }_{2}$ Hollow Spheres. Chemistry of Materials, 21, 5343-5348. http://dx.doi.org/10.1021/cm9028098 
[57] Xuan, S.H., Jiang, W.Q., Gong, X.L., Hu, Y. and Chen, Z.Y. (2009) Magnetically Separable $\mathrm{Fe}_{3} \mathrm{O}_{4} / \mathrm{TiO}_{2} \mathrm{Hollow}$ Spheres: Fabrication and Photocatalytic Activity. Journal of Physical Chemistry C, 113, 553-558. http://dx.doi.org/10.1021/jp8073859

[58] Sun, C., Liu, L., Qi, L., Li, H., Zhang, H., Li, C., et al. (2011) Efficient Fabrication of $\mathrm{ZrO}_{2}$-Doped TiO ${ }_{2}$ Hollow Nanospheres with Enhanced Photocatalytic Activity of Rhodamine B Degradation. Journal of Colloid and Interface Science, 364, 288-297. http://dx.doi.org/10.1016/j.jcis.2011.07.055

[59] Li, W.B., Bu, Y.Y. and Yu, J.Q. (2012) Preparation of $\mathrm{ZnO} / \mathrm{In}_{2} \mathrm{O}_{3}$ Composite Hollow Spheres and Their Photoelectrocatalytic Properties to Glucose Degradation. Acta Physical-Chimica Sinica, 28, 2676-2682. http://dx.doi.org/10.3866/PKU.WHXB201207101

[60] Zhang, C., Yin, L., Zhang, L., Qi, Y. and Lun, N. (2012) Preparation and Photocatalytic Activity of Hollow ZnO and ZnO-CuO Composite Spheres. Materials Letters, 67, 303-307. http://dx.doi.org/10.1016/j.matlet.2011.09.073

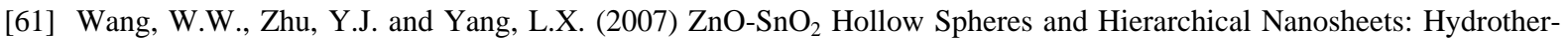
mal Preparation, Formation Mechanism, and Photocatalytic Properties. Advanced Functional Materials, 17, 59-64. http://dx.doi.org/10.1002/adfm.200600431

[62] Liang, J., Xu, J., Long, J., Zhang, Z. and Wang, X. (2013) Self-Assembled Micro/Nano-Structured $\mathrm{Zn}_{2} \mathrm{GeO}_{4} \mathrm{Hollow}$ Spheres: Direct Synthesis and Enhanced Photocatalytic Activity. Journal of Materials Chemistry A, 1, 10622-10625. http://dx.doi.org/10.1039/c3ta12183f

[63] Chen, A.X. (2007) Preparation of $\mathrm{ZrTiO}_{4}$ Composite Hollow Spheres and Their Photocatalytic Properties (Jinan). M.E. Thesis, Shangdong University, Jinan.

[64] Dai, X.J., Luo, Y.S., Zhang, W.D. and Fu, S.Y. (2010) Facile Hydrothermal Synthesis and Photocatalytic Activity of Bismuth Tungstate Hierarchical Hollow Spheres with an Ultrahigh Surface Area. Dalton Transactions, 39, 3426-3432. http://dx.doi.org/10.1039/b923443h

[65] Lu, Y., Luo, Y., Xiao, H.M. and Fu, S.Y. (2014) Novel Core-Shell Structured $\mathrm{BiVO}_{4}$ Hollow Spheres with an UltraHigh Surface Area as Visible-Light-Driven Catalyst. CrystEngComm, 16, 5059-6065. http://dx.doi.org/10.1039/c4ce00379a

[66] Chen, X., Liu, J., Wang, H., Ding, Y., Sun, Y. and Yan, H. (2013) One-Step Approach to Novel $\mathrm{Bi}_{4} \mathrm{~V}_{2} \mathrm{O}_{11}$ Hierarchical Hollow Microspheres with High Visible-Light-Driven Photocatalytic Activities. Journal of Materials Chemistry A, 1, 877-883. http://dx.doi.org/10.1039/c2ta00312k

[67] Tian, G., Chen, Y., Zhou, W., Pan, K., Dong, Y., Tian, C., et al. (2011) Facile Solvothermal Synthesis of Hierarchical Flower-Like $\mathrm{Bi}_{2} \mathrm{MoO}_{6}$ Hollow Spheres as High Performance Visible-Light Driven Photocatalysts. Journal of Materials Chemistry, 21, 887-892. http://dx.doi.org/10.1039/c0jm03040f

[68] Li, X., Huang, R., Hu, Y., Chen, Y., Liu, W., Yuan, R., et al. (2012) A Templated Method to $\mathrm{Bi}_{2} \mathrm{WO}_{6}$ Hollow Microspheres and Their Conversion to Double-Shell $\mathrm{Bi}_{2} \mathrm{O}_{3} / \mathrm{Bi}_{2} \mathrm{WO}_{6}$ Hollow Microspheres with Improved Photocatalytic Performance. Inorganic Chemistry, 51, 6245-6250. http://dx.doi.org/10.1021/ic300454q

[69] Zhang, N., Ouyang, S., Kako, T. and Ye, J. (2012) Synthesis of Hierarchical $\mathrm{Ag}_{2} \mathrm{ZnGeO}_{4}$ Hollow Spheres for Enhanced Photocatalytic Property. Chemical Communications, 48, 9894-9896. http://dx.doi.org/10.1039/c2cc34738e

[70] Li, G., Liu, F. and Zhang, Z. (2010) Enhanced Photocatalytic Activity of Silica-Embedded $\mathrm{TiO}_{2}$ Hollow Microspheres Prepared by One-Pot Approach. Journal of Alloys and Compounds, 493, L1-L7. http://dx.doi.org/10.1016/j.jallcom.2009.12.046

[71] Zhao, W., Feng, L., Yang, R., Zheng, J. and Li, X. (2011) Synthesis, Characterization, and Photocatalytic Properties of Ag Modified Hollow $\mathrm{SiO}_{2} / \mathrm{TiO}_{2}$ Hybrid Microspheres. Applied Catalysis B: Environmental, 103, 181-189. http://dx.doi.org/10.1016/j.apcatb.2011.01.025

[72] Zhang, L., Li, X., Chang, Z. and Li, D. (2011) Preparation, Characterization and Photoactivity of Hollow N, Co CoDoped $\mathrm{TiO}_{2} / \mathrm{SiO}_{2}$ Microspheres. Materials Science in Semiconductor Processing, 14, 52-57. http://dx.doi.org/10.1016/j.mssp.2011.01.004

[73] Li, X., Gao, Y., Yu, L. and Zheng, L. (2010) Template-Free Synthesis of CdS Hollow Nanospheres Based on an Ionic Liquid Assisted Hydrothermal Process and Their Application in Photocatalysis. Journal of Solid State Chemistry, 183, 1423-1432. http://dx.doi.org/10.1016/j.jssc.2010.04.001

[74] Luo, M., Liu, Y., Hu, J., Liu, H. and Li, J. (2012) One-Pot Synthesis of CdS and Ni-Doped CdS Hollow Spheres with Enhanced Photocatalytic Activity and Durability. ACS Applied Materials \& Interfaces, 4, 1813-1821. http://dx.doi.org/10.1021/am3000903

[75] Yu, X., Yu, J., Cheng, B. and Huang, B. (2009) One-Pot Template-Free Synthesis of Monodisperse Zinc Sulfide Hollow Spheres and Their Photocatalytic Properties. Chemistry: A European Journal, 15, 6731-6739. http://dx.doi.org/10.1002/chem.200900204

[76] Zhang, J., Liu, S., Yu, J. and Jaroniec, M. (2011) A Simple Cation Exchange Approach to Bi-Doped ZnS Hollow 
Spheres with Enhanced UV and Visible-Light Photocatalytic $\mathrm{H}_{2}$-Production Activity. Journal of Materials Chemistry, 21, 14655-14662. http://dx.doi.org/10.1039/c1jm12596f

[77] Rengaraj, S., Venkataraj, S., Tai, C., Kim, Y., Repo, E. and Sillanpää, M. (2011) Self-Assembled Mesoporous Hierarchical-Like $\mathrm{In}_{2} \mathrm{~S}_{3}$ Hollow Microspheres Composed of Nanofibers and Nanosheets and Their Photocatalytic Activity. Langmuir, 27, 5534-5541. http://dx.doi.org/10.1021/la104780d

[78] Meng, X., Tian, G., Chen, Y., Zhai, R., Zhou, J., Shi, Y., et al. (2013) Hierarchical CuS Hollow Nanospheres and Their Structure-Enhanced Visible Light Photocatalytic Properties. CrystEngComm, 15, 5144-5149. http://dx.doi.org/10.1039/c3ce40195b

[79] Zhu, H., Lian, C. and Wu, D. (2011) Room-Temperature Synthesis of (Ag, Cu) 2 S Hollow Spheres by Cation Exchange and Their Optical Properties. Materials Chemistry and Physics, 127, 24-27. http://dx.doi.org/10.1016/j.matchemphys.2011.02.023

[80] Yu, J.G., Zhang, J. and Liu, S.W. (2010) Ion-Exchange Synthesis and Enhanced Visible-Light Photoactivity of CuS/ ZnS Nanocomposite Hollow Spheres. Journal of Physical Chemistry C, 114, 13642-13649. http://dx.doi.org/10.1021/jp101816c

[81] Bhirud, A., Chaudhari, N., Nikam, L., Sonawane, R., Patil, K., Baeg, J.O., et al. (2011) Surfactant Tunable Hierarchical Nanostructures of $\mathrm{CdIn}_{2} \mathrm{~S}_{4}$ and Their Photohydrogen Production under Solar Light. International Journal of Hydrogen Energy, 36, 11628-11639. http://dx.doi.org/10.1016/j.ijhydene.2011.06.061

[82] Xing, C., Zhang, Y., Wu, Z., Jiang, D. and Chen, M. (2014) Ion-Exchange Synthesis of Ag/Ag $\mathrm{S}_{\mathrm{Agg}} \mathrm{CuS}_{2} \mathrm{Ternary}_{\mathrm{Ho}}$ llow Microspheres with Efficient Visible-Light Photocatalytic Activity. Dalton Transactions, 43, 2772-2780. http://dx.doi.org/10.1039/c3dt52875h

[83] Subagio, D.P., Srinivasan, M., Lim, M. and Lim, T.T. (2010) Photocatalytic Degradation of Bisphenol-A by NitrogenDoped $\mathrm{TiO}_{2}$ Hollow Sphere in a Vis-LED Photoreactor. Applied Catalysis B: Environmental, 95, 414-422. http://dx.doi.org/10.1016/j.apcatb.2010.01.021

[84] Ao, Y., Xu, J., Fu, D. and Yuan, C. (2009) Visible-Light Responsive C,N-Codoped Titania Hollow Spheres for X-3B Dye Photodegradation. Microporous and Mesoporous Materials, 118, 382-386. http://dx.doi.org/10.1016/j.micromeso.2008.09.010

[85] Bu, D. and Zhuang, H. (2013) Biotemplated Synthesis of High Specific Surface Area Copper-Doped Hollow Spherical Titania and Its Photocatalytic Research for Degradating Chlorotetracycline. Applied Surface Science, 265, 677-685. http://dx.doi.org/10.1016/j.apsusc.2012.11.080

[86] Yin, W., Wang, W. and Sun, S. (2010) Photocatalytic Degradation of Phenol over Cage-Like $\mathrm{Bi}_{2} \mathrm{MoO}_{6}$ Hollow Spheres under Visible-Light Irradiation. Catalysis Communications, 11, 647-650. http://dx.doi.org/10.1016/j.catcom.2010.01.014

[87] Liu, J., Zhang, G., Yu, J.C. and Guo, Y. (2013) In Situ Synthesis of $\mathrm{Zn}_{2} \mathrm{GeO}_{4}$ Hollow Spheres and Their Enhanced Photocatalytic Activity for the Degradation of Antibiotic Metronidazole. Dalton Transactions, 42, 5092-5099. http://dx.doi.org/10.1039/c2dt32623j

[88] Dong, F., Lee, S.C., Wu, Z., Huang, Y., Fu, M., Ho, W.K., et al. (2011) Rose-Like Monodisperse Bismuth Subcarbonate Hierarchical Hollow Microspheres: One-Pot Template-Free Fabrication and Excellent Visible Light Photocatalytic Activity and Photochemical Stability for NO Removal in Indoor Air. Journal of Hazardous Materials, 195, 346-354. http://dx.doi.org/10.1016/j.jhazmat.2011.08.050

[89] Ai, Z.H., Zhang, L.Z. and Lee, S.C. (2010) Efficient Visible Light Photocatalytic Oxidation of NO on Aerosol FlowSynthesized Nano-Crystalline $\mathrm{InVO}_{4}$ Hollow Microspheres. Journal of Physical Chemistry C, 114, 18594-18600. http://dx.doi.org/10.1021/jp106906s

[90] Ikeda, S., Kobayashi, H., Ikoma, Y., Harada, T., Yamazaki, S. and Matsumura, M. (2009) Structural Effects of Titanium(IV) Oxide Encapsulated in a Hollow Silica Shell on Photocatalytic Activity for Gas-Phase Decomposition of Organics. Applied Catalysis A: General, 369, 113-118. http://dx.doi.org/10.1016/j.apcata.2009.09.008

[91] Zhou, C., Zhao, Y., Bian, T., Shang, L., Yu, H., Wu, L.Z., et al. (2013) Bubble Template Synthesis of $\mathrm{Sn}_{2} \mathrm{Nb}_{2} \mathrm{O}_{7} \mathrm{Hol}_{-}$ low Spheres for Enhanced Visible-Light-Driven Photocatalytic Hydrogen Production. Chemical Communications, 49, 9872-9874. http://dx.doi.org/10.1039/c3cc45683h

[92] Zhang, Y.J., Li, X.J., Min, C., Wang, Y.C. and Li, S. (2010) Preparation of NiO-CdS Composite Hollow Spheres and Their Application for $\mathrm{H}_{2}$-Production to Water Photodegradation. China Patent No. CN101623644.

[93] Zhang, Y.J., Li, X.J., Min, C., Wang, Y.C. and Li, S. (2010) Preparation of Composite Hollow Spheres with p-n Junction and Their Application for $\mathrm{H}_{2}$-Production to Water Photodegradation. China Patent No. CN101623645.

[94] Tu, W.G., Zhou, Y., Liu, Q., Tian, Z., Gao, J., Chen, X., et al. (2012) Robust Hollow Spheres Consisting of Alternating Titania Nanosheets and Graphene Nanosheets with High Photocatalytic Activity for $\mathrm{CO}_{2}$ Conversion into Renewable Fuels. Advanced Functional Materials, 22, 1215-1221. http://dx.doi.org/10.1002/adfm.201102566 
[95] Feng, X., Yang, L., Guan, Q. and Liu, Y.L. (2010) Preparation of Ag-Doped $\mathrm{TiO}_{2}$ Hollow Spheres and Their Antibacterial Activity. Ecological Science, 29, 251-255.

[96] Hu, L., Chen, M., Shan, W., Zhan, T., Liao, M., Fang, X., et al. (2012) Stacking-Order-Dependent Optoelectronic Properties of Bilayer Nanofilm Photodetectors Made from Hollow ZnS and ZnO Microspheres. Advanced Materials, 24, 5872-5877. http://dx.doi.org/10.1002/adma.201202749 
Scientific Research Publishing (SCIRP) is one of the largest Open Access journal publishers. It is currently publishing more than 200 open access, online, peer-reviewed journals covering a wide range of academic disciplines. SCIRP serves the worldwide academic communities and contributes to the progress and application of science with its publication.

Other selected journals from SCIRP are listed as below. Submit your manuscript to us via either submit@scirp.org or Online Submission Portal.
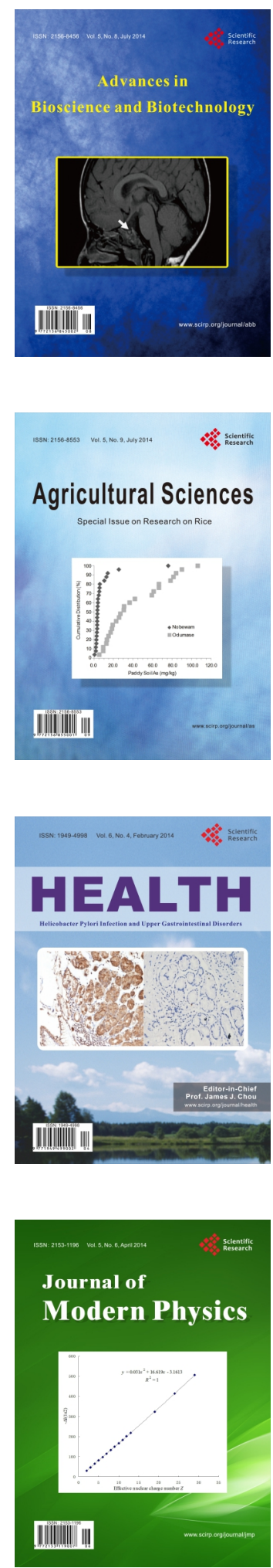
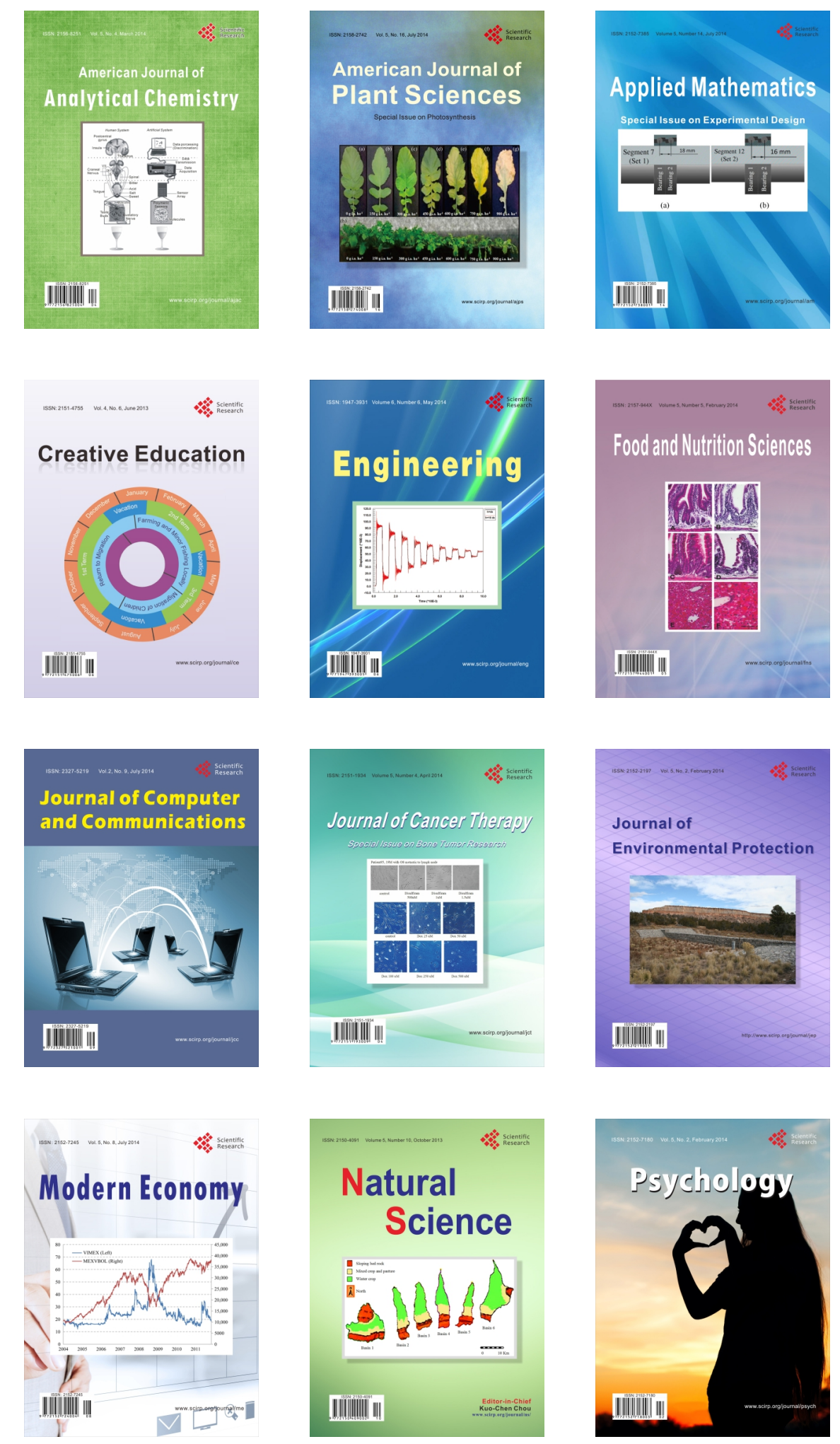